\title{
工科院校材料化学理科专业贯通创新型人才培养探索与实践
}

王宇, 陈刚, 王艳芳, 张兴文, 徐平 ${ }^{*}$

哈尔滨工业大学化工与化学学院, 哈尔滨 150001

摘要: 大力培养创新型人才是当今社会高等院校人才培育任务的重中之重, 而工科院校理科专业更应尽快完善符合 自身特色的创新型人才培养模式。本文论述了哈尔滨工业大学理科省一流专业材料化学专业在本研贯通式人才培养 过程中, 通过教学改革、强化实践、分类培养等一系列措施, 凝练出创新人才培养和专业建设的融合之路, 形成具 有理工结合特色的创新型人才培养模式。

关键词: 理工结合; 创新人才; 教学改革; 分类培养; 贯通式

中图分类号: G64; O6

\section{Exploration and Practice of Cultivating Inter-Disciplinary and Innovative Talents in the Science Major of the College of Engineering}

\author{
Yu Wang, Gang Chen, Yanfang Wang, Xingwen Zhang, Ping Xu * \\ School of Chemistry and Chemical Engineering, Harbin Institute of Technology, Harbin 150001, China.
}

\begin{abstract}
Making great efforts to train innovative talents is the priority of human resource development in universities, and the science majors in engineering colleges should rapidly perfect the cultivation mode of innovative talents conforming to their own characteristics. The paper discusses the cultivation mode of inter-disciplinary and innovative talents in the province first-class major of materials chemistry at Harbin Institute of Technology. We develop a novel talent training model with engineering characteristics by carrying out a series of measures such as teaching reform, strengthening practice, classified cultivation, forming an innovative talent training model with the characteristics of combining science and technology.
\end{abstract}

Key Words: Combination of science and engineering; Innovative talents; Teaching reform;

Classified cultivation; Inter-discipline

\section{1 概述}

创新离不开创新教育, 培养创新人才既是我国战略发展的需要, 也是高校教育教学改革中需要 攻克的一项课题, 如何构建科学有效的人才培养体系则是攻克这项课题的关键。近年来, 我们根据 党的教育方针及高等工科教育对创新人才培养的要求, 通过工科化学课程及相关学科人才培养的探 索与实践, 遵循 “以学生为中心, 厚基础、强实践、重创新” 教育理念, 采取 “融创相携, 因类施 教” 的本研贯通式人才培养模式, 确立了哈尔滨工业大学材料化学专业创新人才培养的定位与特色: 即融入工科思维, 创新育人理念, 将理工结合特色贯穿于本、研教学及育人体系中, 这也是与理科 化学教学和人才培养的根本区别所在。有别于一般大众型、适应型人才培养模式, “本研贯通式人

收稿: 2021-08-18; 录用: 2021-09-16; 网络发表: 2021-10-13

“通讯作者, Email: pxu@hit.edu.cn

基金资助：黑龙江省教育科学 “十四五” 规划 2021 年度重点课题(GJB1421034) 
才培养”把对学生科研能力和创新意识的培养贯穿于本科、研究生的培养全过程 ${ }^{[1,2]}$ 。

\section{2 创新人才培养理念}

贯通式培养模式是整合优质教育资源, 优化人才培养体系, 对本科教育与研究生教育进行有效 衔接的一体化培养模式, 也是国内外大学普遍提倡和遵循的人才培养方式 ${ }^{[3-6]}$ 。哈尔滨工业大学材料 化学专业从本科阶段起, 通过导师制和大学生创新创业项目的实施, 使学生得到基本的科研和创新 训练; 在研究生阶段通过分类培养, 明确创新方向, 进一步强化其科研能力和创新能力。在人才贯 通式培养过程中, 主要形成了四个理念:

(1) “理工结合” 的课程构建。结合工科院校学科背景, 在本科生及研究生基础课讲授中始终将 工科特色贯穿于整个课程体系, 注重理论与工程、理论与科研的结合, 使课程的工科特色更加突出, 学以致用。

(2) “以研促专” 的教学机制。加强学生专业基础教育的内涵更新和外延拓展, 将高水平、创新 性的科研成果融入到课堂教学和实验教学, 形成了以科研促进课程教学、以科研促进专业学习, 有 利于培养学生创新意识和创新能力的教学机制。

(3) “无缝连接” 的学研体系。从本科生科技创新活动开始, 通过科技创新这一平台实现本研学 习与研究的自然连接, 使学生创新能力的培养分层次、按步骤、有目标地进行。

(4) “量体裁衣” 的培养模式。在本科生与研究生的 “贯通式” 人才培养模式下, 根据学生的性 格、特长和创新能力, 有针对性地通过分类培养的方式打造不同类型的拔尖创新人才。

\section{3 培养方法}

本研贯通式创新人才培养模式注重以课程建设为 “点”, 以学科专业建设为 “面”, 形成 “点” “面” 结合的培养机制; 通过课程建设扩大人才培养的广度, 通过学科专业建设加深人才培 养的深度, 实现工科拔尖创新人才的培养目标。

\section{1 创新为本形成课程体系贯通}

\subsection{1 课程教学中凝练创新思维}

与传统理科院校课程不同, 在课程及学科建设中, 应注重 “融入理工思维, 创新育人理念”, 将理论一应用-创新的思维方式始终贯通融合于本科生及研究生的课堂及实践教学中, 从而形成课程 的创新思维方式, 做到教学方法、教学目标统一的要求和标准。

(1) 本研课程理念一致。将传统的 “指导-接受” 转变为 “探索-发现” 的教学模式, 让学生独立 探索课程内容与自身科研方向的契合点, 进而使学生在科研工作中发现创新点。注重科学和课程理 论结合, 教师分享理论学科前沿成果, 拓展学生在相关领域的视野, 让学生接触最新研究成果的原 始文献, 锻炼学生文献阅读和分析能力, 进而掌握科学研究的思路和方法。注重教学体系构建, 基 础课程教学中让学生切身体会科学家是如何在具体实验基础上通过发现现象 $\rightarrow$ 提炼共性 $\rightarrow$ 提出理 论, 建立一个新的学说(归纳创新), 并通过理论指导 $\rightarrow$ 因地制宜 $\rightarrow$ 实际应用, 去指导具体实践的过程 (演绎创新), 使学生了解理论学科课程的基本思维方法, 培养他们的创新理念。

(2) 小班化授课提升创新思维培养成效。为了充分完成课程讨论, 基于学生为主体的教学理念, 专业逐步实施小班制授课及项目式学习(PBL)教学模式, 主要就是在课堂讨论、课下交流以及网络作 业等环节(如早期使用微博留言, 近些年主要是雨课堂、校内SPOC等方式), 利用设问和讨论方式从 已知的现象或前沿科学中提炼出与课程内容相关的实际问题, 引导学生主动利用即时分析、课堂讨 论等方式来解决这些问题, 如果学科的课程体系教学旨在教会学生 “是什么”, 那么促进研究生参与 科研工作则要启发他们去思考 “为什么”。培养学生提出 “为什么”, 研究 “为什么”, 解决 “为什么” 的综合能力, 就是在科研过程中培养了主动创新型的思维模式。依据课堂教学, 在本科教学中, 鼓 励教师通过问题探究、案例分享、分组讨论环节设置, 帮助学生获取隐藏在各种知识背后的智慧, 
培养学生思考、分析和探求真理的综合能力, 使其成为创新型人才。

(3) 以多学科融合教学启发创新思维。研究生导师鼓励指导学生跨专业、学科选课, 使其跳出本 学科的既定思维模式, 以其他学科的现象、分析方法或者理论知识尝试解决其研究课题中的科学难 点。有效拓宽与提升研究生多学科知识水平, 培养创新型人才 “解决问题” 的能力。

\subsection{2 以课程教学指导创新活动}

基础课程教学中结合工科院校教师既做基础科学研究同时具有工程应用背景的特点, 形成科学 研究及工程应用实例与理论融合的教学方式。从大一学期无机化学教学开始进行 “引领”, 以课程 知识讲解 “实验过程” 与微观形貌关系, 介绍相关科研工程实践与大一创新年度计划相关的知识体 系结构, 如沉淀转化形成空心结构, 应用电极电势刻蚀贵金属形成框架结构, 用面包制备航天泡沫 碳等相关SCI文献及专利进展, 发掘SCI论文和专利在材料设计方面存在的问题, 并结合学院教师的 工程实践背景, 找出材料可能应用方向, 与大二、大三开展的实践类课程更好衔接, 以材料设计理 念引导学生产生创新兴趣, 形成初步的创新意识, 学生在这个阶段发表了多篇基于兴趣的教学相 关文章 ${ }^{[7-10]}$ 。大二之后的物化、有机、分析课程注重理论的 “深化” , 将无机化学课程中的热力学部 分、结构部分、平衡部分分别与物化、有机、分析课程进行有效衔接, 加强创新的理论深度, 在物 化、有机内容中介绍专业教师研究相关的光催化、电极、复合膜等材料中 “材料-结构-性能” 机理 关系, 用身边实际材料、课程理论进行实训训练。在大三、大四的功能材料、材料分析测试技术、 薄膜材料制备技术、计算化学等专业课程内容中, 主要为拓宽学生知识面, 鼓励学生将自己的创新 创业项目与课程内容结合, 启发学习。而在研究生阶段课程是对以往课程的进一步 “强化” 衔接, 强调理论深度和知识创新, 重点学习新知识、新方法, 跟踪学科前沿, 最终形成贯通的课程结构。

近些年, 结合人才培养构建方式及课程改革, 专业内基础课程建设成果显著, 物理化学课程为 省精品课程, 无机化学MOOC课程获首批国家精品在线开放课程, 无机化学、有机化学、物理化学 均获得省一流本科课程, 并以一流课程支撑一流专业, 材料化学专业被评为省一流本科专业。结合 改革方式，已获批国家级教改项目1项，省重点及一般教改项目 10余项，校教改项目 20 余项。

\subsection{3 实践教学中提升学生创新能力}

专业建设过程中重视实践教学工作, 突出工科特色。

(1) 与企业合作找实验课程方向。与理科院校倾向于研究基础领域前沿理论的特点相比, 工科 院校特点是与企事业单位合作较多, 有更多机会开展企业联合进行技术改造、开发及应用方面的科 研工作。因此结合学院建设了众多学研基地, 专业教师在校内重视实践、实训内容。专业结合课程 理论和教师的企业横向课题方向推出材料化学综合实验、功能材料设计实验、材料化学课程设计等 内容, 以企业需求为导向, 开展实验教学工作, 整个实践课程比重占整个大学学分比重超 $25 \%$ 。

(2) 以国家战略需求凸显实践创新方式。利用学校航天特色, 在实验室内利用已有的理论知识、 技术基础进行新知识、新技术创造活动的过程对学生起到了最好的示范作用, 如结合膜材料制备内 容介绍专业教师在航天领域相关成果, 在 “风云四号” 气象卫星的干涉式大气垂直探测仪中, 使用 了系内教师研制和生产的低挥发、抗辐照、高太阳吸收率超黑涂层和胶膜, 及为确保 “天问一号” 环绕器上五星红旗材质能历经太空环境考验, 使用了系内教师开发出的集抗辐照、低挥发和耐高低 温交变等性能于一体的特种功能材料等等, 结合这些身边领域应用的课程思政内容, 激发学生参与 实验、创新实验的热情。这些实践内容引入与学科前沿接轨, 避免了专业课教材滞后与科研快速更 新之间的矛盾, 实现本科生-研究生培养的高起点。

结合教学及人才培养成效, 获省教学成果一等奖1项、二等奖1项, 校教学成果一等奖 3 项、二等 奖2项, 并依托本专业教学成果, 学院获中国学位与研究生教育学会研究生教育成果二等奖1项。编 写了符合工科教学特色的 “十一五” 国家级规划教材 《物理化学》、“十二五” 工信部研究生规划教 材 《高等无机化学》、“双一流” 建设精品出版工程研究生教材《高等材料物理化学》和 “工科基础 化学系列” 教材《有机化学》各一部。 


\section{2 以大创活动为主线, 形成本科到研究生的贯通}

以高规格严要求激发学生创新动力, 让学生认识到大学生创新创业活动既锻炼能力, 同时也会 对研究生阶段的科研工作有较大的促进作用。哈工大材料化学专业2002年建成, 2004年系内教师讨 论开展导师制教学, 导师作为学生引路人, 结合学生学业预期, 进行本硕士、博士阶段的提前规划。 把本科当研究生培养, 硕士当博士培养, 博士当教师培养, 在这种培养模式下, 每个学历毕业的学 生, 在创新能力和论文写作水平及规范性方面都取得了明显的提升, 不自觉地就实现了自身创新能 力的贯通。近年来, 哈工大材料化学专业本科生参加大学生创新创业活动的比例均在 $90 \%$ 以上, 教 师指导大学生创新创业训练计划立项 100 余项, 其中国家级项目 20 余项。参加科技创新学生以第一作 者身份在ACS Appl. Mater. Inter. $(\mathrm{IF}=7.50) 、$ J. Hazard. Mater. $(\mathrm{IF}=6.07)$ 等国际知名刊物上发表SCI论 文 10 余篇。本专业学生 2 次代表哈工大参加全国大学生科技创新论坛, 并获 “卓越杯” 大学生化学新 实验设计竞赛一等奖2次, 挑战杯大学生学术科技作品竞赛二等奖2次。2011年专业本科生获得第七 届 “中国青少年科技创新奖”。在中国科学评价研究中心公布的本科专业排名中, 哈工大材料化学专 业一直为名列前茅的 5 星专业。近两年, 在大类招生模式下, 本科生导师制模式已得到学院认可并在 学院全面开展。

\section{3 以分类拔尖型创新人才为目标, 形成了人才培养的贯通}

通过分类实践 “凝练” 创新方向, 依据本科生、研究生的 “贯通式” 培养模式, 在本科阶段, 结合课堂、实验、大创活动等形式, 初步考查学生能力, 在研究生阶段, 结合分类实践, 确定分类 培养方式。在形成创新理念、具备创新能力的基础上, 进一步根据学生的性格、特长和创新能力为 其进行 “量体裁衣” 式的培养方案设计, 通过 “分类培养” 的方式造就不同类型的拔尖创新人才。 在初步能力考查和个性结构分类的基础上, 形成学生的双轨制培养, 即引导学生分别向研究型和管 理型两个主要的方向发展。让部分自主钻研精神强、基础知识扎实的学生深入前沿领域的基础研究 工作。同时, 鼓励社会能力强、沟通能力强的学生积极参与学生、社会活动, 为将来在管理岗位、 销售岗位的创新思维、创新活动积累经验。通过让研究生在课程学习阶段提前锻炼创新性思维, 接 触创新性活动, 让他们在创新人才成长的道路上凝练出符合自身特点的创新方向。

在贯通培育模式下, 研究生培养的质量得到了极大提升。根据本科阶段学生表现出的能力、优 势和兴趣方向, 在量体裁衣、分类培养的指导思想下, 近年来培养出了以获得全国百篇优秀博士论 文提名奖为代表的科研拔尖人才; 以世界500强某大型国企某公司最年轻总经理和航天科工集团某 所科技管理部长等为代表的管理拔尖人才; 以吉林某环保集团有限公司及宁波市某节能科技有限公 司总经理为代表的创业拔尖人才。在科学研究创新人才培养方面, 2010年以来材料化学专业贯通式 培养研究生连续在Nat. Chem.、J.Am. Chem. Soc.、Angew. Chem. Int. Ed. 及Adv. Mater. 等化学类顶级 期刊上发表了 10 余篇原创性科研工作论文。1人获全国百篇优博论文及提名奖, 5 人获哈工大优博论 文, 3 人获教育部博士生学术新人奖, 2 人获省优秀硕士论文。1团队获哈工大 “十佳研究生团队” 称 号, 2 人获哈工大研究生 “十佳英才” 称号, 3 人获宝钢基金会优秀学生奖。学生骨干活动创新人才 培养方面, 数人担任过哈工大校研究生会副主席及院学生会主席等职务, 1 人代表哈工大参加第六期 全国大学生骨干培训班(哈工大 2 人之一, 担任培训班班长, 获优秀学员称号, 受到胡锦涛同志接见)。 近年来, 由于在人才培养方面的突出贡献, 材料化学系的物理化学学科已成为哈工大参加全国学科 评估的化学龙头学科。

\section{4 结语}

在实现贯通式创新人才培养过程中, 要强化专业教师的 “引领” 作用, 结合院校特点, 鼓励教 师将科研业务融入提升教学。在此基础上, 通过在课程体系教学过程中 “融入” 创新理念, 科研过 程中 “提升” 创新能力, 实践过程中 “凝练” 创新方向, 拓宽化学化工类研究生由 “本科” “研究生” 向 “创新人才” 蜕变的通路。 
[1] 张树鹏, 钟秦, 葛玲玲, 郝艳霞, 董伟. 大学化学, 2019, 34 (11), 103.

[2] 王宇, 赵贞, 陈刚, 裴健, 孙净雪. 实验技术与管理, 2018, 35 (9), 165.

[3] 赵凯博. 黑龙江教育, 2013, No. 5, 73 .

[4] 杨东亮, 徐明生, 黄万武, 查远莉, 李涛. 学位与研究生教育, 2007, No. 5, 73.

[5] 刘劲松, 徐明生. 学位与研究生教育, 2017, No. 2, 47.

[6] 张莉. 学位与研究生教育, 2015, No. 6, 13.

[7] 刘文龙, 张嘉任, 蒋世阳, 胡江涛, 张兴文. 大学化学, 2018, 33 (7), 90.

[8] 杜宣锐, 罗嗣汉邦, 林泽炜, 王宇. 大学化学, 2021, 36 (1), 2003111.

[9] 徐克难, 陈子康, 张云骐, 王宇. 大学化学, 2019, 34 (8), 128.

[10] 张绮殁, 刘天行, 王宇. 大学化学, 2021, 36 (10), 2103032. 